\title{
Characteristics of nanocomposite polymer with temperature variation and heating time by using simple mixing method
}

\author{
Verinazul Septrians yah ${ }^{1 *}$, Anis Saggaff ${ }^{2}$ and Saloma ${ }^{3}$ \\ Master Degree Program in Civil Engineering, Faculty of Engineering, Sriwijaya University, Indonesia ${ }^{1}$ \\ Professor, Civil Engineering Department, Faculty of Engineering, Sriwijaya University, Indonesia ${ }^{2}$ \\ Assistant Professor, Civil Engineering Department, Faculty of Engineering, Sriwijaya University, Indonesia ${ }^{3}$
}

Received: 28-February-2021; Revised: 16-May-2021; Accepted: 20-May-2021

(C)2021 Verinazul Septriansy ah et al. This is an open access article distributed under the Creative Commons Attribution (CC BY)

License, which permits unrestricted use, distribution, and reproduction in any medium, provided the original work is properly cited.

\begin{abstract}
Nanocomposite particles have different structures, compositions and the characteristics. The bonds between the nanocomposite particles play an important role in enhancing and limiting the properties of the material. The more particles interact, the stronger material bond. Polymer concrete has been widely used as a substitute for cement which can produce higher compressive strength in a shorter time through composite engineering thus it is impermeable to water, not affected by $U V$ rays, and resistant to chemicals. Combining the epoxy resin and the hardener materials which have strong characteristics against compressive strength, bending, tensile and modulus added by nanosilica which can increase the maximum strength to form a polymer matrix bond. The composition of a mixture of fine aggregate, epoxy resin, hardener and nanosilica heated at a temperature of $85^{\circ} \mathrm{C}$ for 1 hour can produce a new material that is stronger and slighter than the previous material obtained from a mixture of 38.2\% sand, epoxy resin and hardener with a ratio of 1: 1 and nanosilica levels at $0.28 \%$ by the weight of epoxy resin were obtained with a density of $1,464 \mathrm{~kg} / \mathrm{m} 3$ and a compressive strength of $577.669 \mathrm{~kg} / \mathrm{cm} 2$ with initial and final bonds of 40 and 60 minutes. The characteristics test of Fourier Transform Infrared Spectroscopy (FTIR), Scanning Electron Microscope (SEM) and X-Ray Diffraction (XRD) showed that SiO2 is more dominant and has an amorphous phase, where in this phase the crystal arrangement is not very dominant. The addition at a certain temperature can increase the strength of the nanocomposite material. If it is given a higher temperature, the material has brittle properties which can decrease the strength.
\end{abstract}

\section{Keywords}

Nanocompiste, Polymer concrete, Epoxy resin, Nanosilica.

\section{Introduction}

Advanced technological knowledge, highly influences the achievement of the strong, sturdy and good quality of construction targets. Nanotechnology becomes a massive concern to the scientists around the world in conducting various research and engineering the adjustment of material, size, managing the chemical composition and controlling the interactions between particles. One of them is a nano scale research which is widely applied to nanocomposite materials. The nano-sized particles have a very high interaction surface. The more particles interact, the stronger bond of the material. It makes the bonds between the particles get stronger and the mechanical properties of the material increase. However, the addition of nanoparticles does not always improve its mechanical properties.

\footnotetext{
*Author for correspondence
}

There are certain limitations when adding the nano material, the strength actually decreases. Epoxy resin is defined as a low molecular pre-polymer containing more than one epoxide group. Epoxy resin is an epoxy oligomer, which can form a three-dimensional network of thermosetting materials when it reacts to hardeners [1]. Epoxy is resistant to heat, it has higher mechanical strength and has good corrosion resistance [2]. Epoxy can be used as a material for repairing and connecting the rifts of concrete structures, the plaster layers in brittle concrete structures, and the water proof [3]. Epoxy reacts very easily with hardener when it is mixed, there is a change from initially liquid to solid. With the addition of nanocalcium, epoxy resin and hardener can increase the thermal stability of the material [4]. Epoxy resin is often used as a mixture for glass fiber, carbon, hybrid, and boron graphite. Epoxy resin has several advantages than the polyester resin, such as lower density, higher modulus of elasticity, 
tensile strength, and more heat resistance [5]. The epoxy resin reaction can be shown in Figure 1.

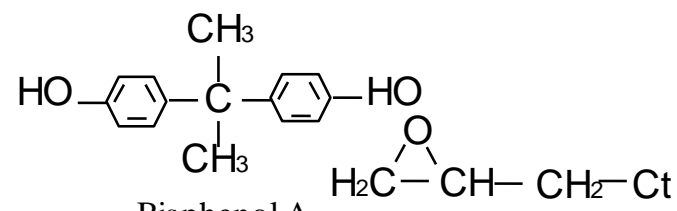

Bisphenol A

Epichlorohydrin

Figure 1 Bisphenol-A and epichlorohydrin

Bisphenol-A is composed from a mixture of orthophthalic and Isophthalic anhydride which has a saturated acid component. Epoxy resin has high mechanical strength and resistant to chemical attack.

Hardener functions as a catalyst or additional material for the reaction and drying process to occur. The percentage of hardener can give different mechanical properties of the epoxy resin, if the percentage of hardener is small, the viscosity of the epoxy resin is reduced and the hardening process takes longer. The excessive percentage of hardenerhas an impact on the hardness of the epoxy resin which becomes brittle and its strength is reduced.

Nanosilica is a unique material that can increase compressive strength higher than without nanosilica [6]. A chemical compound with the $\mathrm{SiO} 2$ molecular form is generally found in silica or quartzite sand. Nanosilica also functions as a filler to increase micro density and an activator in hydration reactions. The size of the nanosilica particles can be used as filler in concrete to produce a denser concrete structure. The nano-sized particles provide better filler benefits compared to micro-based materials [7].

From the explanation above, the characteristics of the material aim to know and understand the process of the material mixture composition, and to analyze the characteristics of the polymer nanocomposite material that will be made. The material characterization process includes mechanical testing, such as compressive strength and density testing, then mineral testing, which includes X-Ray Diffraction testing, Fourier Transform Infrared Spectroscopy (FT-IR) testing and Scanning Electron Microscope (SEM) testing.

\section{Research method}

This research is generally conducted in two stages:

1. Material Manufacturing. At this stage, various compositions of materials were tried which aim to obtain a composition that had the maximum compressive strength. After getting the right results, then do the temperature variations and heating time.

2. Material characteristics. Characterization was carried out to get the physical parameters of the nanocomposite polymer that had been made. If the nanocomposite polymer that has been produced still far from the parameters of the material which has low compressive strength, then sample preparation will be carried out again.

The method used in this research is the Simple Mixing method. In the mixing process of nanosilica, epoxy resin and hardener, a heating process is carried out with a temperature variation of $75^{\circ} \mathrm{C}-105^{\circ} \mathrm{C}$ with a preheating time of 15 minutes to reduce the viscosity of the resin. The mixing of the nanosilica and epoxy resin material is stirred for 10 minutes, after the hardener composite has inserted into the dough with a 1:1 ratio between epoxy resin and hardener then stirred again for 2 minutes followed by the addition of fine aggregate then stirred again with a mixer until the mixture becomes homogeneous. Then the dough quickly puts into a steel mold that has been preheated and greased then the mold is put back into the oven with temperature variations of $75^{\circ} \mathrm{C}, 85^{\circ} \mathrm{C}, 95^{\circ} \mathrm{C}$ and $105^{\circ} \mathrm{C}$ with a heating time of 1 hour, 2 hours and 3 hours. Then cooled it at room temperature to form specimens of research object [8].

Heating is done to remove the solvent so that the solid form of nanocomposite polymer and it has the characterization of slight and super strong materials. The flow diagram of the process in making the nanocomposite materials is shown in Figure 2. From the various temperature and heating time used, several samples may have different results.

To read the material easily, the following code is used: PN: Nanocomposed Polymer.

S: Sand.

EH: Epoxy Resin and Hardener.

$\mathrm{N}$ : Nanosilica.

$\mathrm{T}$ : Temperature.

h: Hour 
The material is heated at $75^{\circ} \mathrm{C}, 85^{\circ} \mathrm{C}, 95^{\circ} \mathrm{C}, 105^{\circ} \mathrm{C}$ for 15 minutes to reduce the viscosity of the resin

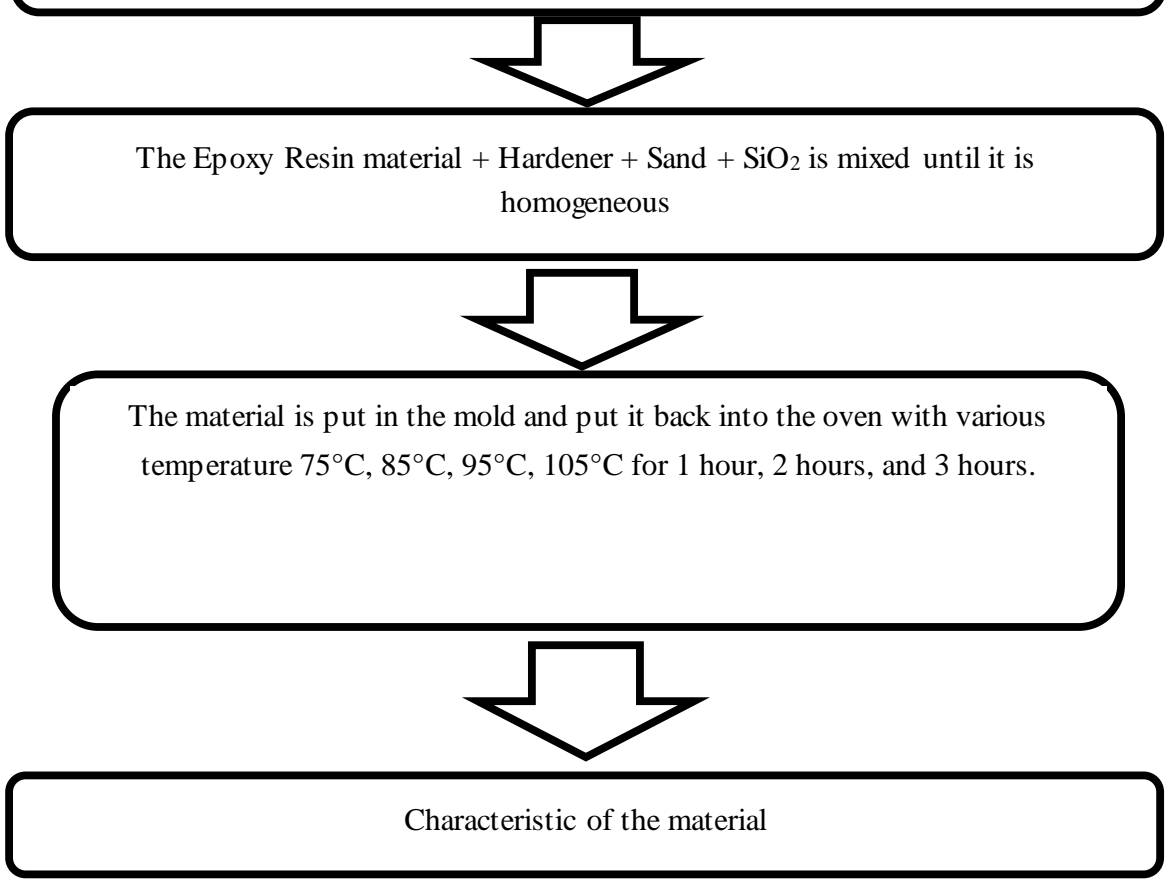

Figure 2 The flow diagram of the nanocomposite material by using the simple mixing method

\section{Results and discussion}

3.1XRD nanosilica test results ( $\mathrm{SiO2}$ )

After carrying out the characterization test with XRD, it showed a typical functional group of silica, the amorphous phase of the silica with a particle size of 15 $\mathrm{mm}$ is shown in Figure 3. Nanosilica particles ( $\mathrm{SiO} 2)$ can increase the strength of a material with a suitable mixing. The mixing of polymer and nanosilica can add the strength to a certain amount, if it is added too much nanosilica, it will make the polymer break easily.

\subsection{Setting time test results}

The setting time test consists of the initial bonding time and the final bonding time, the test refers to the ASTM C191 standard. The results of setting time test with temperature variations can be seen in Figure 4.

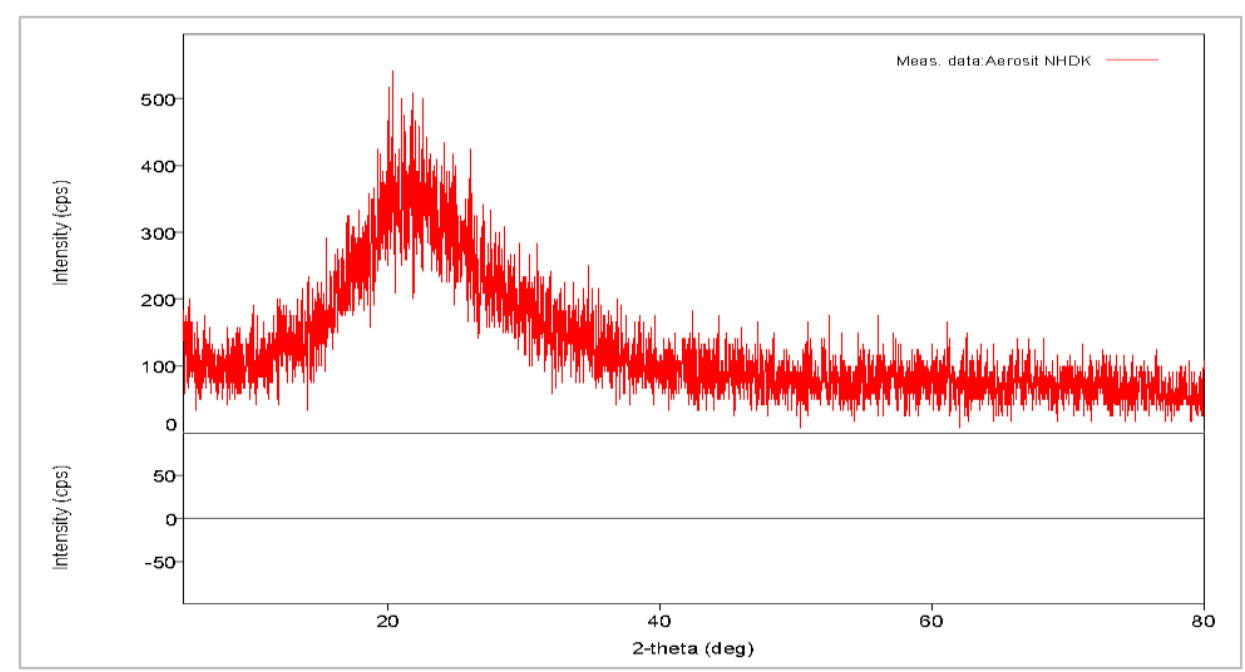

Figure 3 X-Ray diffraction (XRD) 
Verinazul Septriansy ah et al.

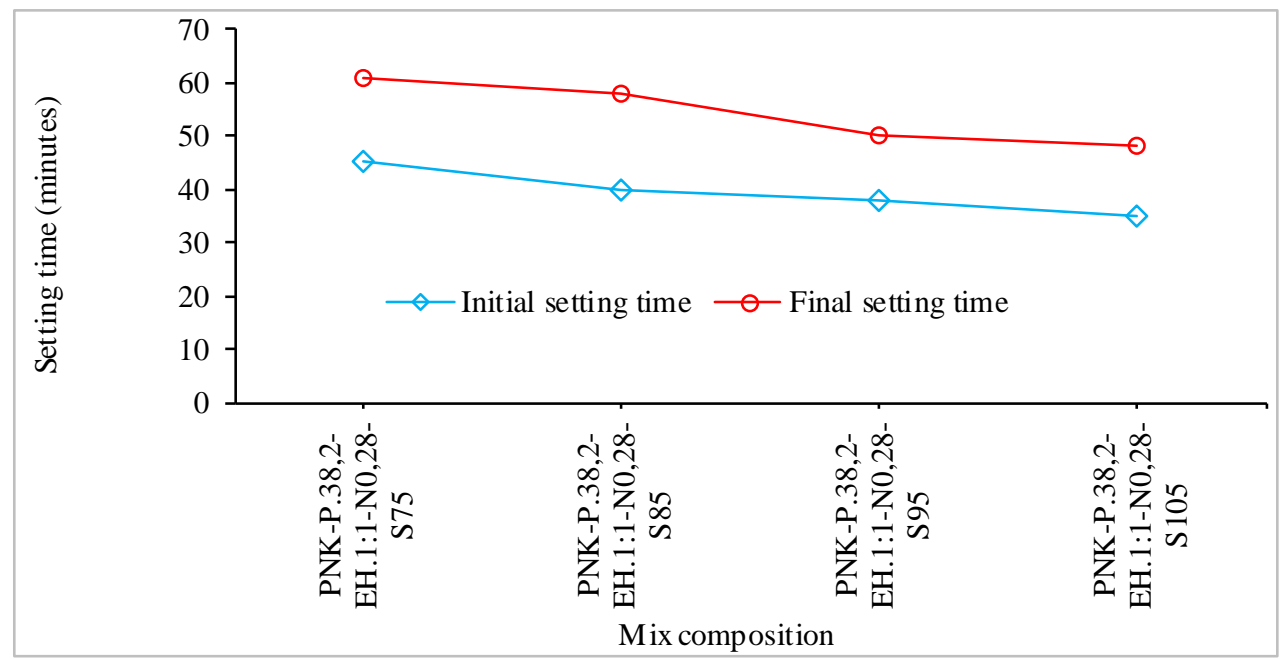

Figure 4 Setting time

In this study, the initial binding time was obtained in the range of 45-35 minutes while the final binding time ranged from $61-48$ minutes. The results of the setting time test showed that the faster initial and final bonds were found in the PN-S.38.2-EH.1:1-N.0.28-T.105 ${ }^{\circ} \mathrm{C}$ mixtures for 35 minutes and 48 minutes. Based on ASTM C 1329-04 the final time is around 90 minutes for the initial time. The higher temperature used can increase the initial bonding time of the mixture.

\subsection{Density test results}

After the polymer concrete manufacturing process is done, a specific gravity test is carried out between
$1,600-1,800 \mathrm{~kg} / \mathrm{m} 3$. The density is done by weighing the weight of the cube test object containing $5 \mathrm{~cm}$ at the age of 7 days and 28 days with the target density achieved as shown in Figure 5 and Figure 6.

The low density of concrete at the age of 7 days is found in the concrete mixture of PN-S.38.2-EH.1:1N.0.28-T.105-3h of $1,401.87 \mathrm{~kg} / \mathrm{m}^{3}$ and the highest is in the mixture of PN-S.38, 2-EH.1:1-N.0 without heating at $1,600 \mathrm{~kg} / \mathrm{m}^{3}$.

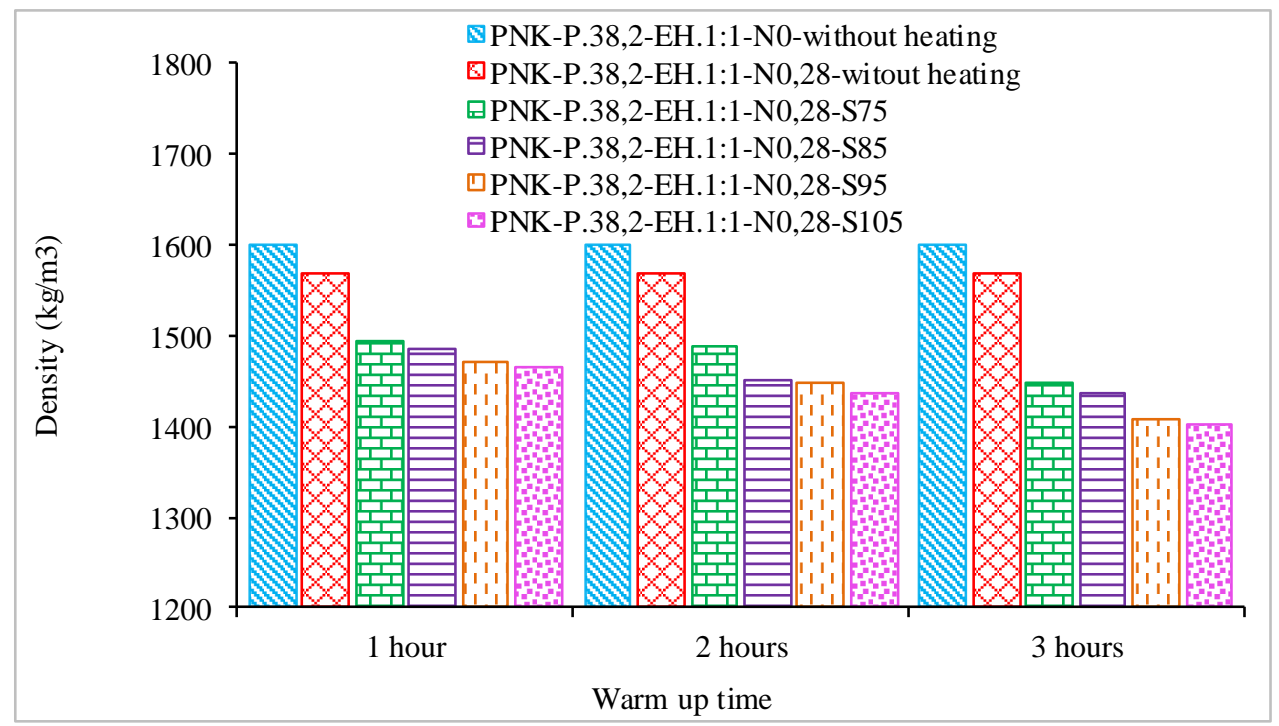

Figure 5 Density in 7 days 


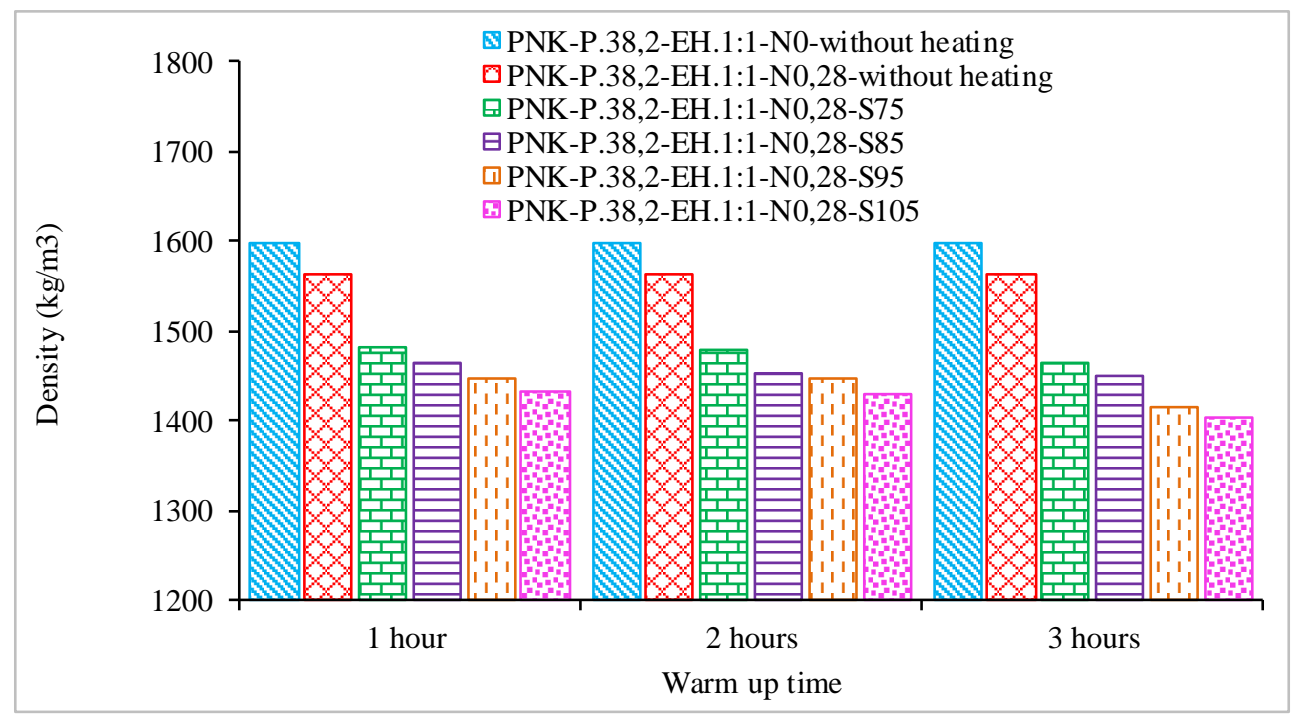

Figure 6 Density in 28 days

Whereas at the age of 28 days the lowest density was found in the PN-S.38.2-EH.1:1-N.0.28-T.105-3h mixture of $1,401.87 \mathrm{~kg} / \mathrm{m}^{3}$ and the highest was in the PN-S.38 mixture of 2-EH.1:1-N.0 without heating at $1,600 \mathrm{~kg} / \mathrm{m}^{3}$. This happens because the high temperature used can affect the decrease in density. The addition of nanosilica to the polymer matrix can increase the density, the higher density of an object, the greater mass of each volume [9].

Based on the results of research conducted [10], it was found that the concrete density was $1,692 \mathrm{Kg} / \mathrm{m}^{3}$ with the ratio of epoxy resin, hardener, fine aggregate and foaming agent when compared to the results of the research conducted, the concrete density was obtained very much lighter by around $17 \%$ which is equal to $1,402.93 \mathrm{~kg} / \mathrm{m}^{3}$.

\subsection{Compressive strength test results}

The compressive strength test was carried out at the age of 7 days and 28 days using a $5 \mathrm{~cm}$ size cube mold. The results of the concrete compressive strength test are shown in Figure 7 and Figure 8.

The results of the concrete compressive strength test with an average value of the cube specimen containing $50 \mathrm{~mm}$. The results of the polymer concrete compressive strength test at the age of 7 days are the greatest in the mixture of PN-S.38.2-EH.1:1-N.0.28T.85-1h of $554.215 \mathrm{Kg} / \mathrm{cm}^{2}$ with a specific gravity of $1,484.27 \mathrm{Kg} / \mathrm{m}^{3}$ while the lowest compressive strength is in the composition of PN-S.38.2-EH.1:1-N.0 without heating process with a compressive strength of $346.704 \mathrm{Kg} / \mathrm{cm}^{2}$.

At the age of 28 days, there was an increase in the compressive strength of the PN-S.38.2-EH.1:1N.0.28-T.85-1h specimen of $577.669 \mathrm{Kg} / \mathrm{cm} 2$ with a specific gravity of $1,464 \mathrm{Kg} / \mathrm{m} 3$ while the lowest compressive strength was at composition of PNS.38,2-EH.1:1-N.0 without heating process with a compressive strength of $346.704 \mathrm{Kg} / \mathrm{cm} 2$.

It shows that temperature highly affects the compressive strength and density of the specimen. According to [11], a drastic change in temperature can cause the compressive power and strength decrease, the level of temperature dependence of the test object produces a higher value at low temperatures while at high temperatures can produce very low strength values.

According to [12], curing is needed to obtain better mechanical properties where in this process there is a more complete cross-linked between the molecules. According to [6], Nanosilica is a unique material that can increase compressive strength higher compared than without nanosilica. According to [13], the addition of nanoparticles can improve its mechanical properties and if it is added excessively, it can cause the strength of the materials decreasing. 
Verinazul Septriansy ah et al.

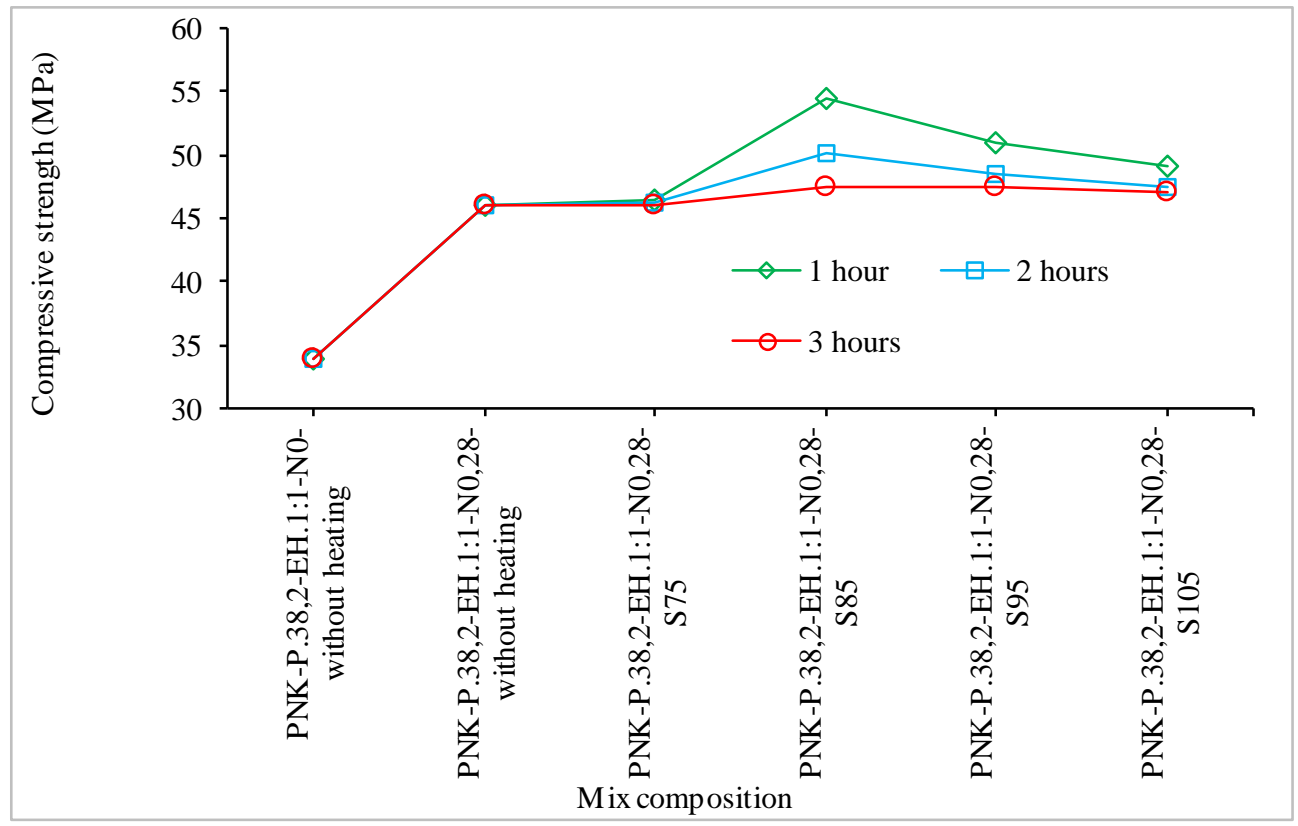

Figure 7 Compressive strength in 7 days

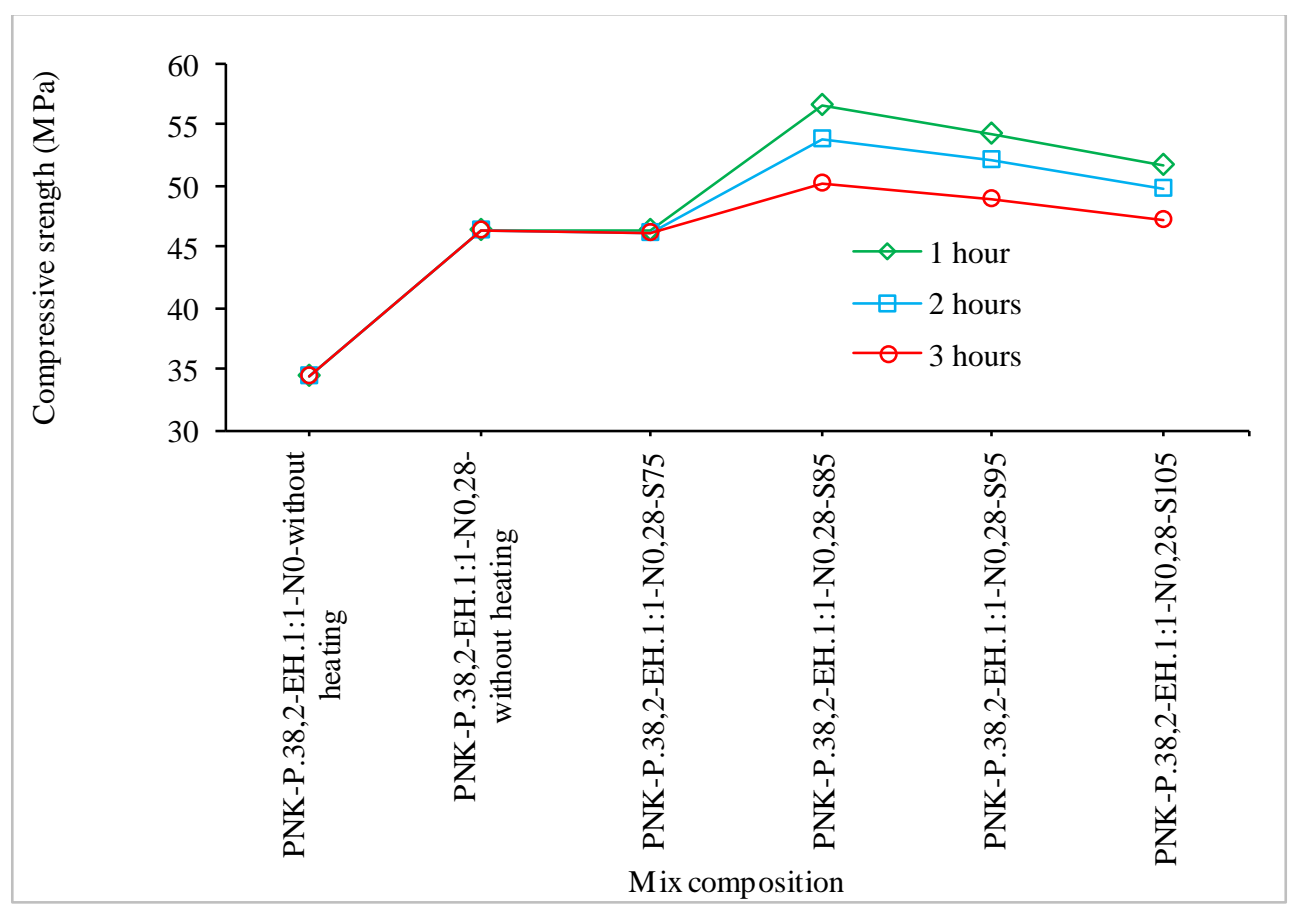

Figure 8 Compressive strength in 28 days

\subsection{XRD test results}

XRD characteristics were carried out to determine the cumulative phase formed at the changed of the temperature. XRD testing is done by diffracting light through a crystal gap. The results show that the nanomaterials with various heating temperature are shown in Figure 9. In Figure 9, the results of the X- ray diffraction pattern have an amorphous phase, wherein this phase identifies the presence of crystals but it is not so dominant. In the PN-P.38.2-EH.1:1N.0.28 sample with a temperature of $85^{\circ} \mathrm{C}$ for 1 hour, there is a peak that indicates the number of elements identified. 
The results showed that the nanomaterial with a temperature variation of $85^{\circ} \mathrm{C}$ showed different results by the appearance of a diffraction pattern with some of the highest peaks (Figure 10). After changing the temperature, the peaks of the diffraction begin to coalesce into one peak. The sharp peak pattern indicates that the sample has a crystalline structure due to the presence of strange objects in the material, thus inhibiting the formation of the amorphous phase. Crystalline structures are avoided because they are less reactive and the characteristics of the resulting material will be less good.
It is broadly stated that the amorphous structure is more correct than the crystal structure due to the greater movement and location of the adjacent atoms so that it plays a role in the strength of the paste [14], thus allowing nanomaterials with this percentage to bind other materials when mixing the material. Based on the diffraction pattern, the percentage of arm of can be calculated by using the total area method [15]. The percentage value of the nanomaterial structure with temperature variations is shown in Table 1.

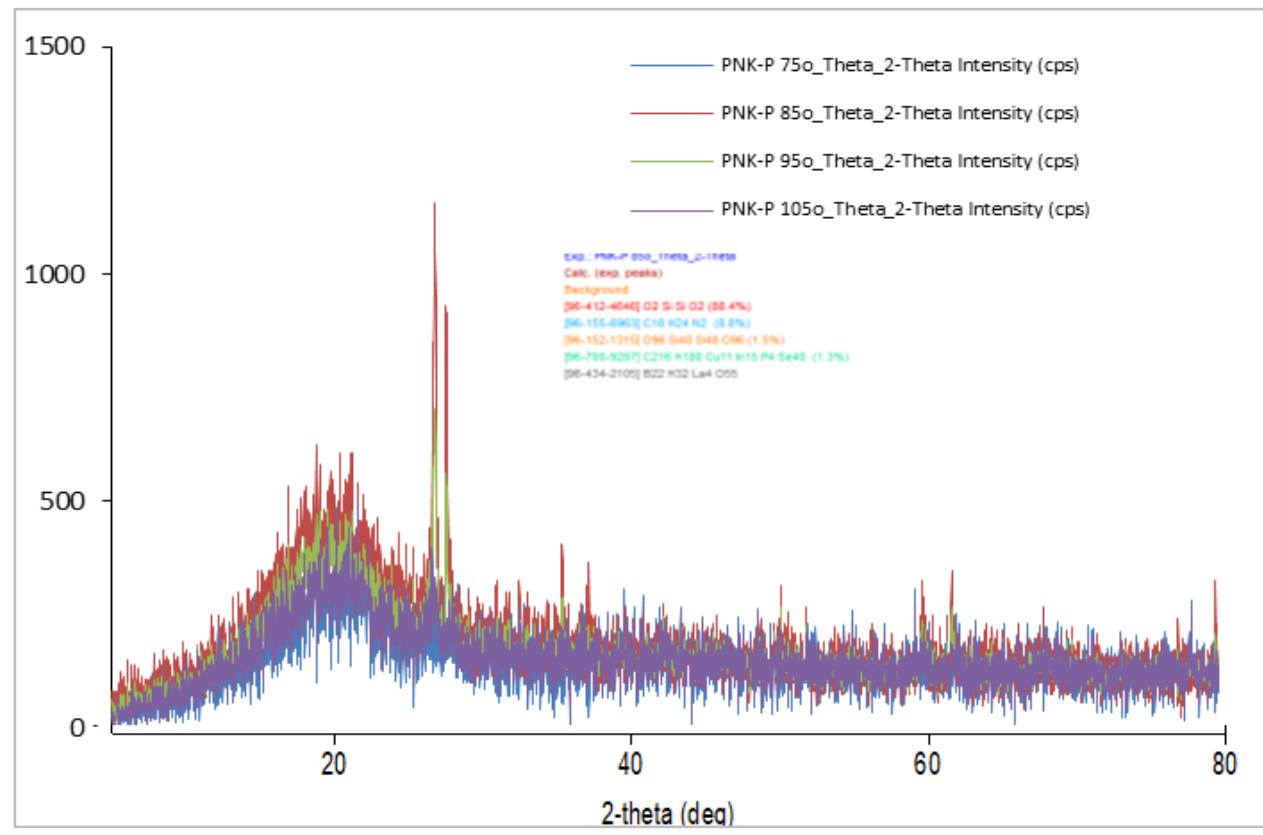

Figure 9 XRD analys is of a fine powder

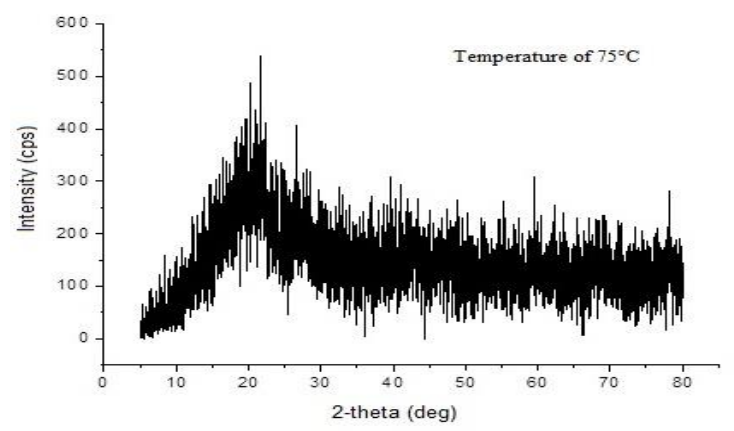

(a) Temperature $75^{\circ} \mathrm{C}$

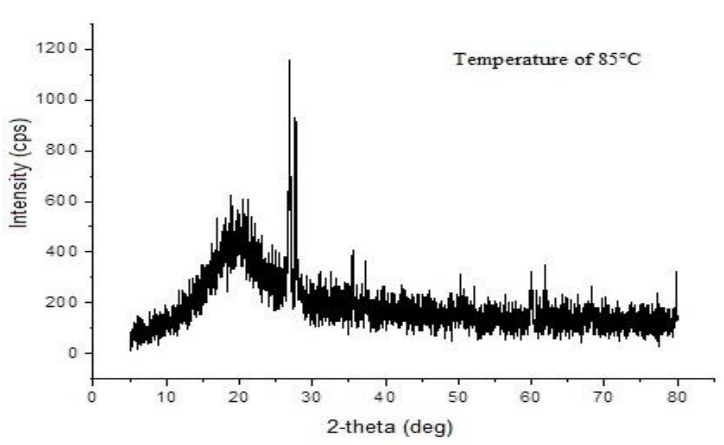

(b) Temperature $85^{\circ} \mathrm{C}$ 
Verinazul Septriansy ah et al.

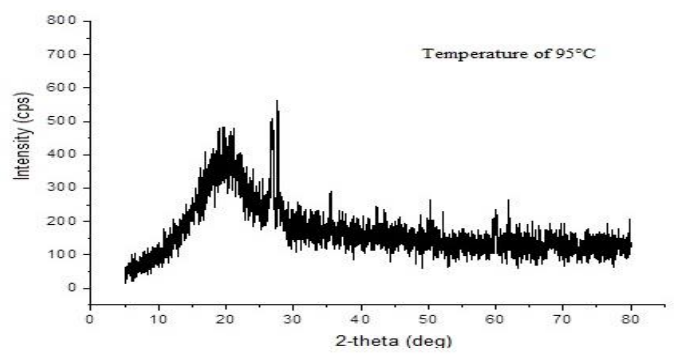

(c) Temperature $95^{\circ} \mathrm{C}$

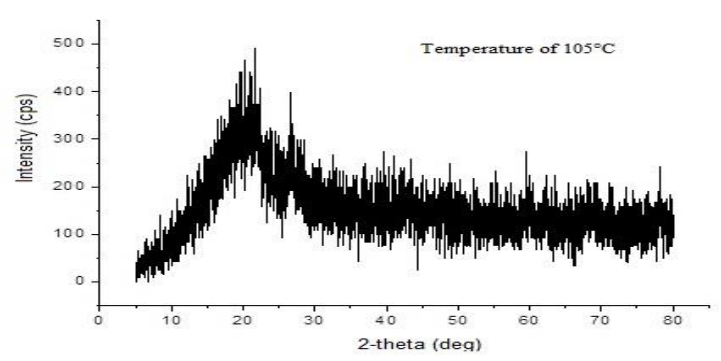

(d) Temperature $75^{\circ} \mathrm{C}$

Figure 10 XRD measurement results in (a) temperature $75^{\circ} \mathrm{C}$, (b) temperature $85^{\circ} \mathrm{C}$, (c) temperature of $95^{\circ} \mathrm{C}$ and (d) temperature of $105^{\circ} \mathrm{C}$

Table 1 The percentage of arm of nanomaterial structure

\begin{tabular}{lll}
\hline Temperature & Crystalline \% & Arm of \% \\
\hline PN-P.38.2-EH.1:1-N.0.28-S75 & 9,754 & 90,246 \\
PN-P.38,2-EH.1:1-N.0.28-S85 & 9,650 & 90,335 \\
PN-P.38,2-EH.1:1-N.0.28-S95 & 8,445 & 89,984 \\
PN-P.38,2-EH.1:1-N.0.28-S105 & 10,083 & 89,917 \\
\hline
\end{tabular}

Based on the percentage value of the arm of nanomaterial structure, the results obtained not that far from other temperatures. The highest percentage of arm of is at $85^{\circ} \mathrm{C}$ and the lowest percentage of arm of is at $105^{\circ} \mathrm{C}$.

\subsection{FT-IR test result}

The FT-IR test is carried out on the materials with temperature variations. The results which are obtained, then interpreted by using the correlation table and the comparis on are shown in Table 2. From Table 2, it can be seen that there is a difference between the temperature variation of $105^{\circ} \mathrm{C}$ which has an $\mathrm{O}-\mathrm{H}$ stretch that is not found in other materials, while in other materials there is a bend in $\mathrm{C}-\mathrm{H}$ and the $\mathrm{SiO} 2$ bond has almost the same bond. In the materials with temperatures of $75^{\circ} \mathrm{C}, 85^{\circ} \mathrm{C}$ and $95^{\circ} \mathrm{C}$, there are 6 types of bonds, such as $\mathrm{C}-\mathrm{H}, \mathrm{C}-\mathrm{C}, \mathrm{CO} 2, \mathrm{NO} 2$, $\mathrm{SiO} 2$ and $\mathrm{C}-\mathrm{H}$ bending while at the temperatures of $105^{\circ} \mathrm{C}$ there are seven $\mathrm{O}-\mathrm{H}, \mathrm{C}-\mathrm{H}, \mathrm{C}-\mathrm{C}, \mathrm{CO} 2, \mathrm{NO} 2$, $\mathrm{SiO} 2$ bonds and $\mathrm{C}-\mathrm{H}$ bending. The $\mathrm{SiO} 2$ group is determined from the chart with the characterized by a high peak with a large gap width.

Table 2 The Interpretation of FT-IR material Test

\begin{tabular}{|c|c|c|c|c|c|c|c|c|}
\hline \multirow{2}{*}{ Vibrasi } & \multicolumn{2}{|c|}{$\begin{array}{l}\text { PN- Temperatures } \\
{75^{\circ} \mathrm{C}}\end{array}$} & \multicolumn{2}{|c|}{$\begin{array}{l}\text { PN- Temperatures } \\
{85^{\circ} \mathrm{C}}\end{array}$} & \multicolumn{2}{|c|}{$\begin{array}{l}\text { PN- Temperatures } \\
{95^{\circ} \mathrm{C}}^{\text {Pat }}\end{array}$} & \multicolumn{2}{|c|}{$\begin{array}{l}\text { PN- Temperatures } \\
105^{\circ} \mathrm{C}\end{array}$} \\
\hline & $\begin{array}{l}v \\
\left(\mathrm{~cm}^{-1}\right)\end{array}$ & $\% \mathrm{~T}$ & $\begin{array}{l}v \\
\left(\mathrm{~cm}^{-1}\right)\end{array}$ & $\% \mathrm{~T}$ & $\begin{array}{l}v \\
\left(\mathrm{~cm}^{-1}\right)\end{array}$ & $\% \mathrm{~T}$ & $\begin{array}{l}\mathbf{v} \\
\left(\mathrm{cm}^{-1}\right)\end{array}$ & $\% \mathrm{~T}$ \\
\hline $\mathrm{O}-\mathrm{H}$ & - & - & - & - & - & - & 3650,33 & 104,800 \\
\hline $\mathrm{C}-\mathrm{H}$ & 2981,19 & 103,478 & 2981,28 & 105,057 & 2981,04 & 99,931 & 2981,44 & 105,439 \\
\hline $\mathrm{C}-\mathrm{C}$ & 2159,75 & 90,399 & 2159,24 & 90,719 & 2159,57 & 89,533 & 2159,45 & 90,262 \\
\hline $\mathrm{CO}_{2}$ & 2029,62 & 92,576 & 2029,33 & 93,034 & 2031,92 & 91,716 & 2031,84 & 92,482 \\
\hline $\mathrm{NO}_{2}$ & 1509,94 & 99,285 & 1509,49 & 100,273 & 1508,82 & 95,799 & 1508,84 & 99,097 \\
\hline $\mathrm{SiO}_{2}$ & 1052,44 & 64,537 & 1050,49 & 76,917 & 1051,88 & 59,613 & 1032,93 & 64,760 \\
\hline C-H & 777,66 & 80,497 & 777,07 & 90,027 & 776,66 & 78,053 & 777,19 & 85,065 \\
\hline
\end{tabular}

The absorption of the $\mathrm{OH}$ group with a theoretical $3700-3000 \mathrm{~cm}^{-1}$, there is an alcohol compound with a hydrogen stretching vibration environment, for the absorption of the $\mathrm{CH}$ group with a theoretical 2853 $2962 \mathrm{~cm}^{-1}$, there is an aliphatic hydrogen compound with a double bond environment, for the $\mathrm{CC}$ group with a theoretical 2190-2260 $\mathrm{cm}^{-1}$ indicates the presence of alkynes compounds, $\mathrm{CO}$ absorption with a theoretical 2000-2300 $\mathrm{cm}^{-1}$ there is an ester compound with two double bonds, the presence of $\mathrm{NO}_{2}$ groups that arise due to the presence of nitrogen compounds (Figure 11). According to [13], the addition of nano $\mathrm{SiO}_{2}$ changes the type of bonding that occurs in the nanocomposite material. 

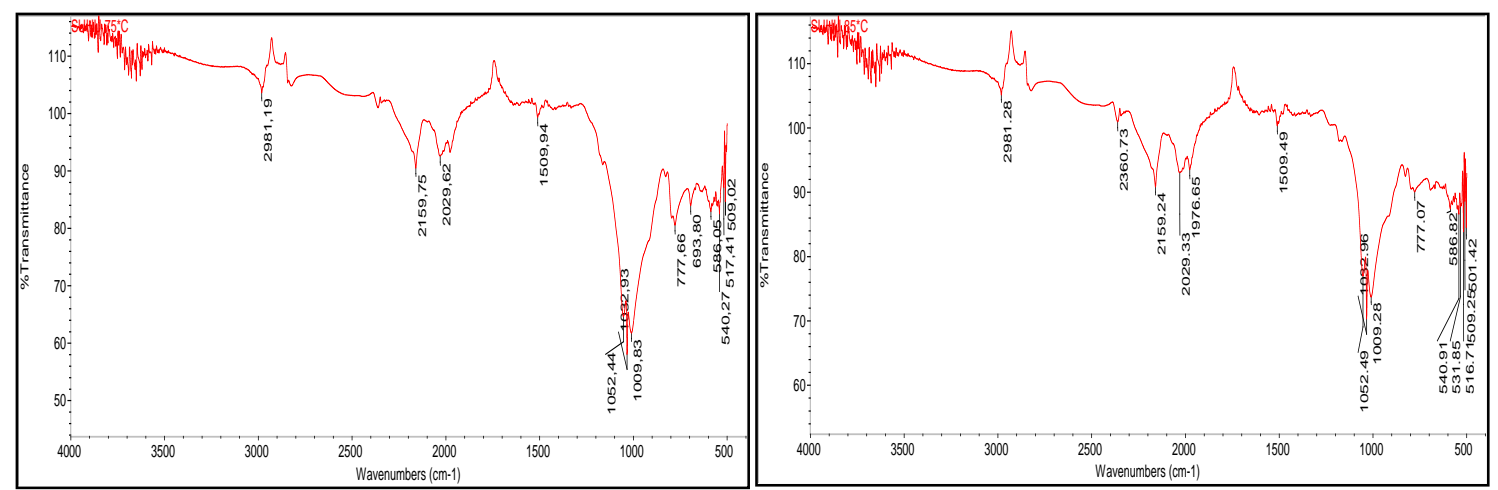

(a) PN-temperature $75^{\circ} \mathrm{C}$

(b) PN-temperature $85^{\circ} \mathrm{C}$

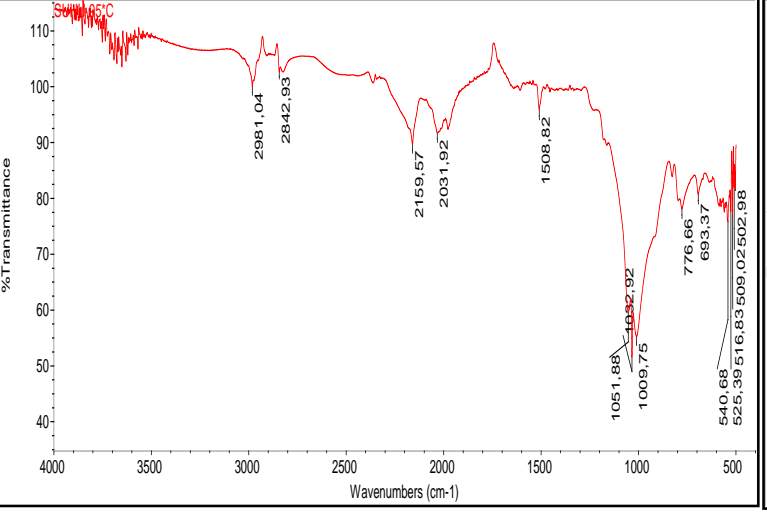

(c) PN-temperature $95^{\circ} \mathrm{C}$

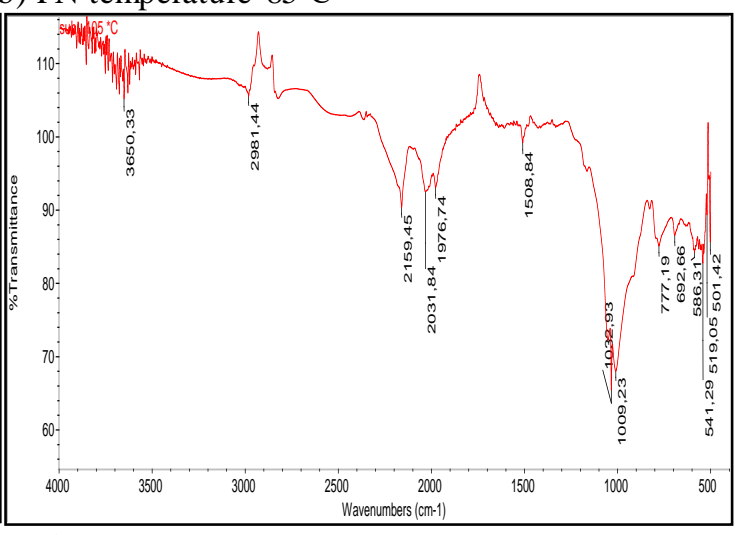

(d) PN-temperature $105^{\circ} \mathrm{C}$

Figure 11 FTIR test results (A) PN-Temperature $75^{\circ} \mathrm{C}$; (B) PN-Temperature $85^{\circ} \mathrm{C}$; (C) PN-Temperature $95^{\circ} \mathrm{C}$; (D) PN-Temperature $105^{\circ} \mathrm{C}$

\subsection{SEM test results}

The effect of nanocomposites has a very significant influence on the properties of the material with a homogeneous mixture that can increase the strength well. According to [13], the SEM testing with a mixture of nano $\mathrm{SiO} 2$ and epoxy concluded that a good dispersion can occur by modifying the surface of the nanoparticles with appropriate processing so that the nanoparticles will fill the molecular cavity and provide a better network shape.

SEM test results show that the higher temperature, the specimens tend to have brittle properties with a smoother fracture surface as shown in Figure 12.

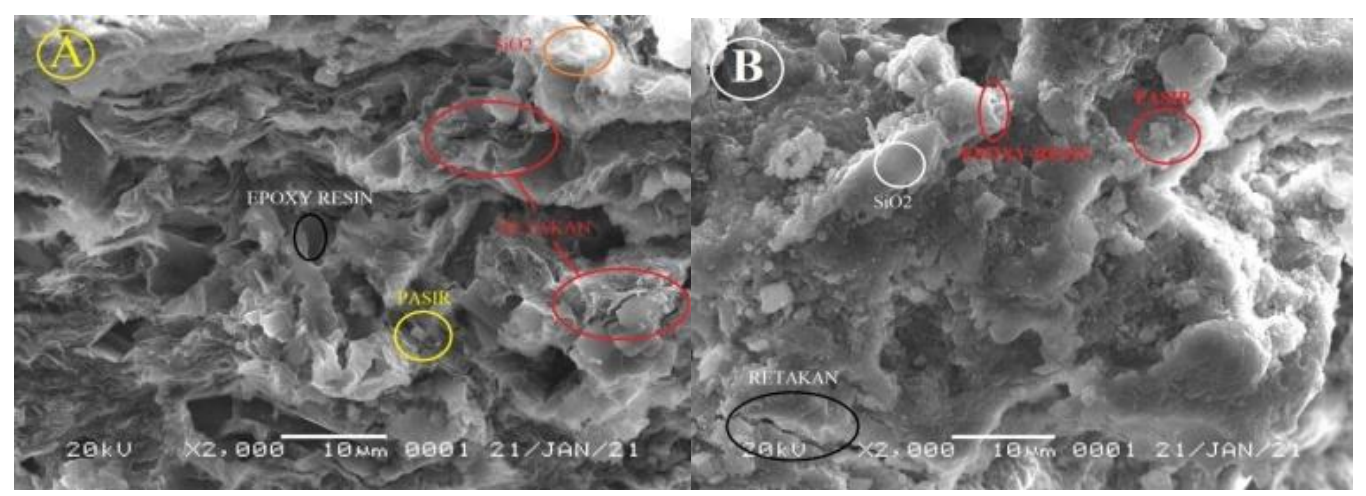

(a) PN-temperature $75^{\circ} \mathrm{C}$

(b) PN-temperature $85^{\circ} \mathrm{C}$ 


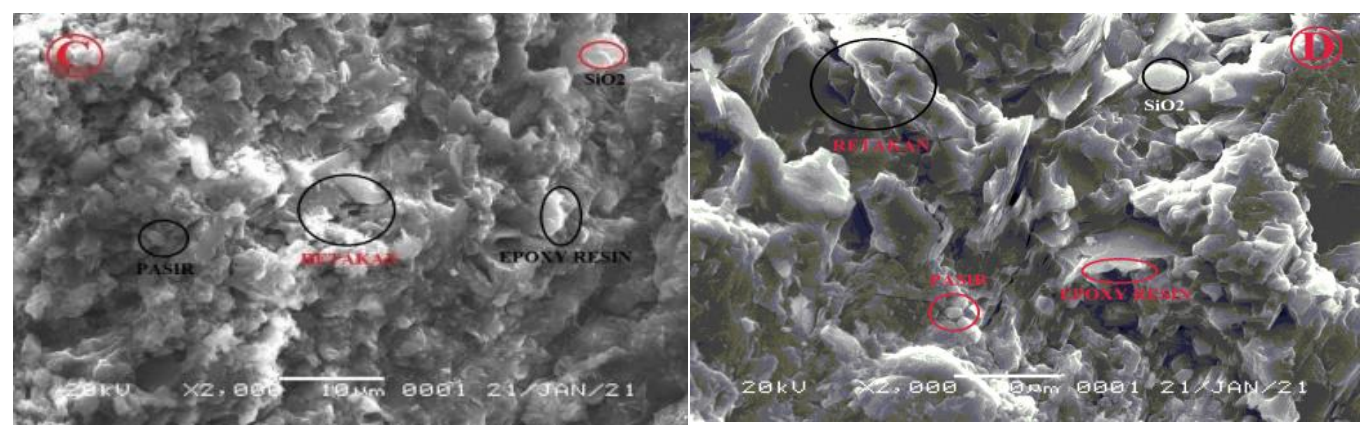

(c) PN-temperature $95^{\circ} \mathrm{C}$

(d) PN-temperature $105^{\circ} \mathrm{C}$

Figure 12. SEM test results (A) PN-Temperature $75^{\circ} \mathrm{C}$, (B) PN-Temperature $85^{\circ} \mathrm{C}$, (C) PN-Temperature $95^{\circ} \mathrm{C}$, (D) PN-Temperature $105^{\circ} \mathrm{C}$

\section{Conclusion}

The composition of a mixture of nanosilica, epoxy resin, hardener and fine aggregates produces slight polymer concrete with greater strength than ordinary lightweight concrete.

From the standard weight of slight concrete between $1,200-1,700 \mathrm{~kg} / \mathrm{m} 3$, the test results showed that the test material meets the slight concrete standard. The addition of sand to the specimens aims to save costs in making lightweight concrete but has high quality concrete. The ratio of epoxy, nanosilica, and fine aggregate is very influential with the specific gravity that has been done. The more use of nanosilica, the smaller impact on the density.

Fine-grained aggregate provides higher mechanical strength as filler because it has a high molecular density. The maximum compressive strength produced in the composition of a mixture from fine aggregate, epoxy resin, hardener and nanosilica with oven temperature at $85^{\circ} \mathrm{C}$ for 1 hour is obtained with a density of $1,464 \mathrm{~kg} / \mathrm{m} 3$ and a compressive strength of $577.669 \mathrm{~kg} / \mathrm{cm} 2$.

In the measurement results using XRD testing, it can be seen that X-ray diffraction has an amorphous phase, where in this phase the crystal arrangement is identified but not so dominant, in samples with temperature variations where the highest content is in $\mathrm{SiO} 2$ with a composition of $88.4 \%$. At $85^{\circ} \mathrm{C}$ the percentage of arm of increases slightly. The higher heating temperature, the lower arm of percentage.

The FT-IR characteristics are used to determine what bonds are in the nanocomposite material when it was given with some temperature variations. The difference that occurs at $105^{\circ} \mathrm{C}$ in the presence of $\mathrm{O}-$ $\mathrm{H}$ compounds while at $75^{\circ} \mathrm{C}$ to $95^{\circ} \mathrm{C}$ has the same six bonds. In other words, the addition of temperature 660 variations does not show changes in the types of bonds that occur in the nanocomposite material.

SEM test results show that the higher temperature, the material experiences brittle properties where the surface texture of the fractions looks smoother. From the results of this research, it can be concluded that the addition at a certain temperature can increase the compressive strength of the nanocomposite material and if it is given a higher temperature, the nanocomposite material has brittle character which causes the material compressive strength become weak.

\section{Acknowledgment}

The research presented in this paper was supported by Matching Grant Sriwijaya University-Universiti Teknologi Malay sia 2020.

\section{Conflicts of interest}

The authors have no conflicts of interest to declare.

\section{References}

[1] Ma H, Zhang X, Ju F, Tsai SB. A study on curing kinetics of nano-phase modified epoxy resin. Scientific Reports. 2018; 8:1-15.

[2] Dümichen E, Javdanitehran M, Erdmann M, Trappe V, Sturm H, Braun U, et al. Analyzing the network formation and curing kinetics of epoxy resins by in situ near-infrared measurements with variable heating rates. Thermochimica Acta. 2015; 616:49-60.

[3] Wan J, Bu ZY, Xu CJ, Li BG, Fan H. Learning about novel amine-adduct curing agents for epoxy resins: butyl-glycidylether-modified poly (propyleneimine) dendrimers. Thermochimica Acta. 2011; 519(1-2):7282.

[4] Jin FL, Park SJ. Thermal stability of trifunctional epoxy resins modified with nanosized calcium carbonate. Bulletin of the Korean Chemical Society. 2009; 30(2):334-8. 
[5] Zheng Y, Zheng Y, Ning R. Effects of nanoparticles $\mathrm{SiO} 2$ on the performance of nanocomposites. Materials Letters. 2003; 57(19):2940-4.

[6] Zhang J, Xu YC, Huang P. Effect of cure cycle on curing process and hardness for epoxy resin. Express Poly mer Letters. 2009; 3(9):534-41.

[7] Golestaneh M, Amini G, Najafpour GD, Beygi MA. Evaluation of mechanical strength of epoxy polymer concrete with silica powder as filler. World Applied Sciences Journal. 2010; 9(2):216-20.

[8] Nasution A, Imran I, Abdullah M. Improvement of concrete durability by nanomaterials. Procedia Engineering. 2015; 125:608-12.

[9] Ahmad T, Mamat O, Ahmad R. Studying the effects of adding silica sand nanoparticles on epoxy based composites. Journal of Nanoparticles. 2013.

[10] Juanda O, Saggaff A, Hanafiah H, Saloma S. Phy sical and mechanical properties of lightweight polymer concrete with epoxy resin. International Journal of Scientific \& Technology Research. 2019; 8(7):857-63.

[11] Petersen HN, Thomason JL, Minty R, Brøndsted P, Kusano Y, Almdal K. Testing temperature on interfacial shear strength measurements of epoxy resins at different mixing ratios. In 20th international conference on composite materials 2015(pp.1-7). ICCM 20 Secretariat.

[12] Dang W, Kubouchi M, Yamamoto S, Sembokuya H, Tsuda K. An approach to chemical recycling of ep oxy resin cured with amine using nitric acid. Polymer. 2002; 43(10):2953-8.

[13] Nikje M, Khanmohammadi M, Garmarudi A, Haghshenas M. Nanosilica reinforced epoxy floor coating composites: preparation and thermophysical characterization. Current Chemistry Letters. 2012; 1(1):13-20.
[14] Walker RO, Pavía SA. Physical properties and reactivity of pozzolans, and their influence on the properties of lime-pozzolan pastes. Materials and Structures. 2011; 44:1139-50.

[15] Kern A, Madsen IC, Scarlett NV. Quantifying amorphous phases. In uniting electron crystallography and powder diffraction 2012 (pp. 219-31). Springer, Dordrecht.

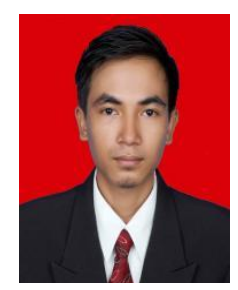

Verinazul Septriansyah is a student in the Civil Engineering Master Program, Faculty of Engineering, Sriwijaya University, Indonesia. His research focuses on Geopolymer Concrete, Nanomaterial Concrete and Lightweight Concrete.

Email: verynazuel@gmail.com

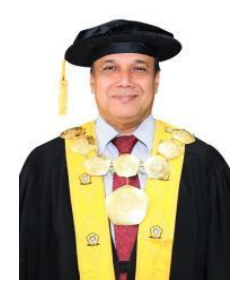

Anis Saggaff is a professor in the Civil Engineering Department, Faculty of Engineering, Sriwijaya University, Indonesia. He received a Doktor in Civil Engineering from Universiti Teknologi Malaysia. He is Rector of Sriwijaya University. His research focuses on Geopolymer Concrete, Nanomaterial Concrete, Lightweight Concrete, Cold-Formed Steel, and Light-weight Construction.

Email: anissaggaf@y ahoo.com

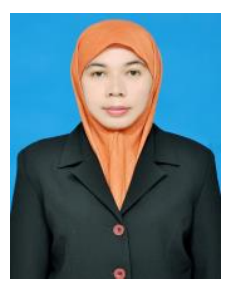

Saloma is a lecturer in the Civil Engineering Department, Faculty of Engineering, Sriwijaya University, Indonesia. She received a Doktor in Civil Engineering from Institut Teknologi Bandung in 2014. She is Head of Graduate of Civil Engineering at Sriwijaya University. Her research focuses on Geopolymer Concrete, Nanomaterial Concrete, Lightweight Concrete, Reactive Powder Concrete, SelfCompacting Concrete, Cold-Formed Steel, and Light-weight Construction

Email: salomaunsri@gmail.com 